\title{
Loss-of-function mutations in the CABLES1 gene are a novel cause of Cushing's disease
}

\author{
Laura C Hernández-Ramírez', Ryhem Gam², Nuria Valdés1,3, Maya B Lodish', \\ Nathan Pankratz ${ }^{4}$, Aurelio Balsalobre², Yves Gauthier², Fabio R Faucz', \\ Giampaolo Trivellin', Prashant Chittiboina5, John Lane4, Denise M Kay6 \\ Aggeliki Dimopoulos7, Stephan Gaillard8,9, Mario Neou8, Jérôme Bertherat8,10, \\ Guillaume Assié8,10, Chiara Villa,11,12, James L Mills7,*, Jacques Drouin²,*, and \\ Constantine A Stratakis ${ }^{1, *}$
}

\author{
1Section on Endocrinology and Genetics, Eunice Kennedy Shriver National Institute of Child Health and \\ Human Development (NICHD), National Institutes of Health (NIH), Bethesda, Maryland, USA \\ ${ }^{2}$ Laboratoire de Génétique Moléculaire, Institut de Recherches Cliniques de Montréal (IRCM), Montréal, \\ Québec, Canada \\ ${ }^{3}$ Service of Endocrinology and Nutrition, Hospital Universitario Central de Asturias, Instituto Universita- \\ rio de Oncología del Principado de Asturias, Universidad de Oviedo, Oviedo, Spain \\ ${ }^{4}$ Department of Laboratory Medicine and Pathology, University of Minnesota Medical School, \\ Minneapolis, Minnesota, USA \\ ${ }^{5}$ Surgical Neurology Branch, National Institute of Neurological Disorders and Stroke (NINDS), National \\ Institutes of Health (NIH), Bethesda, Maryland, USA \\ ${ }^{6}$ Newborn Screening Program, Wadsworth Center, New York State Department of Health, Albany, \\ New York, USA \\ ${ }^{7}$ Division of Intramural Population Health Research, Epidemiology Branch, Eunice Kennedy Shriver \\ National Institute of Child Health and Human Development (NICHD), National Institutes of Health \\ (NIH), Bethesda, Maryland, USA \\ 8Institut Cochin, INSERM U1016, CNRS UMR8104, Université Paris Descartes, Paris, France \\ ${ }^{9}$ Department of Neurosurgery, Hôpital Foch, Suresnes, France \\ ${ }^{10 S}$ ervice d'Endocrinologie, Cochin Hospital, Assistance Publique Hôpitaux de Paris, Paris, France \\ ${ }_{11}$ Department of Pathological Cytology and Anatomy, Hôpital Foch, Suresnes, France \\ ${ }^{12}$ Department of Endocrinology, $\mathrm{CHU}$ de Liège, University of Liège, Liège, Belgium \\ *(J L Mills, J Drouin and C A Stratakis contributed equally to this work)
}

Correspondence should be addressed to C A Stratakis Email stratakc@mail.nih.gov

\begin{abstract}
The CABLES1 cell cycle regulator participates in the adrenal-pituitary negative feedback, and its expression is reduced in corticotropinomas, pituitary tumors with a largely unexplained genetic basis. We investigated the presence of CABLES1 mutations/copy number variations (CNVs) and their associated clinical, histopathological and molecular features in patients with Cushing's disease (CD). Samples from 146 pediatric (118 germline DNA only/28 germline and tumor DNA) and 35 adult (tumor DNA) CD patients were screened for CABLES1 mutations. CNVs were assessed in 116 pediatric $C D$ patients (87 germline DNA only/29 germline and tumor DNA). Four potentially pathogenic missense variants in CABLES1 were identified, two in young adults (c.532G > A, p.E178K and c.718C > T, p.L240F) and two in children (c.935G >A, p.G312D and c.1388A $>$ G, and p.D463G) with CD; no CNVs were found. The four variants affected residues within or close to the predicted cyclin-dependent kinase-3 (CDK3)-binding region of the CABLES1 protein and impaired its ability to block cell growth in a mouse corticotropinoma cell
\end{abstract}

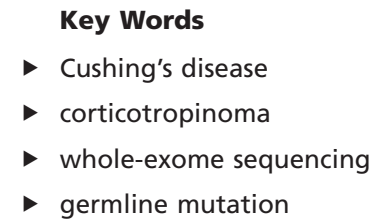

http://erc.endocrinology-journals.org DOI: 10.1530/ERC-17-0131
(C) 2017 The authors Published by Bioscientifica Ltd. Printed in Great Britain

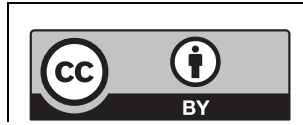

This work is licensed under a Creative Commons Attribution 3.0 Unported License. 
line (AtT20/D16v-F2). The four patients had macroadenomas. We provide evidence for a role of CABLES1 as a novel pituitary tumor-predisposing gene. Its function might link two of the main molecular mechanisms altered in corticotropinomas: the cyclindependent kinase/cyclin group of cell cycle regulators and the epidermal growth factor receptor signaling pathway. Further studies are needed to assess the prevalence of CABLES1 mutations among patients with other types of pituitary adenomas and to elucidate the pituitary-specific functions of this gene.

\section{Introduction}

In recent years, germline defects in multiple genes have been linked to the pathogenesis of pituitary adenomas, both with syndromic and isolated presentation (Caimari \& Korbonits 2016). In contrast with other types of pituitary tumors, corticotropinomas are infrequent in patients with 'classic' multiple endocrine neoplasia and have rarely been described in the setting of familial isolated pituitary adenoma (FIPA) (Stratakis et al. 2010, Cazabat et al. 2012). Consequently, the germline abnormalities leading to corticotroph cell tumorigenesis remain largely unknown. On the other hand, somatic mutations in the USP8 gene hotspot are highly prevalent among corticotropinomas in adult and pediatric patients, but they have not been detected in other types of pituitary adenomas (PérezRivas et al. 2015, Reincke et al. 2015). Therefore, it might be that the majority of the corticotropinomas are caused by disruptions in molecular pathways that are not shared by other pituitary tumor types.

The CABLES1 (Cdk5 and ABL enzyme substrate 1) gene (18q11.2) is a negative regulator of cell cycle progression that is activated in corticotroph cells in response to glucocorticoids (Roussel-Gervais et al. 2016). The physiological negative feedback exerted by glucocorticoids on the corticotroph cells is often impaired in corticotropinomas, and, concordantly, CABLES1 protein expression is lost in around half of such tumors (Roussel-Gervais et al. 2010, Roussel-Gervais et al. 2016). CABLES1 gene inactivation by allelic loss, aberrant splicing or promoter hypermethylation has been observed in different types of human cancers but, to our knowledge, it has not been explored in pituitary adenomas before (Tan et al. 2003, Zhang et al. 2005, Sakamoto et al. 2008). Moreover, there are no human phenotypes reported in association with CABLES1 germline mutations (http:// omim.org/entry/609194, accessed: 28-03-17). Therefore, we investigated the presence of CABLES1 gene mutations and copy number variations (CNV) in a large group of patients with Cushing's disease (CD).

\section{Materials and methods}

\section{Pediatric Cushing's disease cohort}

We studied 146 pediatric ( $<18$ years at diagnosis) patients with CD who are part of a large cohort evaluated at the outpatient clinic and/or admitted for clinical work-up and treatment at the National Institutes of Health (NIH) Clinical Center between 1997 and 2017 and recruited under the research protocol 97-CH-0076 (ClinicalTrials. gov: NCT00001595). The Eunice Kennedy Shriver National Institute of Child Health and Human Development Institutional Review Board approved this study, and informed assent/consent was obtained from all the patients and their parents/guardians. Clinical data were obtained directly from the patients and/or from the Clinical Research Information System. Parents and siblings of the patients were also recruited, when available.

For all the individuals, DNA was extracted either from a peripheral blood sample using the Maxwell 16 Blood DNA Purification Kit in a Maxwell 16 Instrument (Promega AS1015 and AS3050) or from saliva using the Oragene-Dx collection kit and the PrepIT-L2P DNA extraction kit (DNA Genotek OGD-500 and PT-L2P-45), according to the manufacturer's protocols. When available, stained histopathological sections from the corticotropinomas were retrieved from the Department of Pathology. After either manual delimitation of the tumor area or microdissection, DNA was extracted from unstained sections using the Pinpoint Slide DNA Isolation System (Zymo Research D3001). Screening for germline mutations in AIP, CDKN1B, CDKN2C, MEN1, and PRKAR1A in 74 of these patients, and GPR101 in 34 of them, as well as somatic GPR101 defects in 23 corticotropinoma DNA samples from these patients has been reported before (Stratakis et al. 2010, Trivellin et al. 2016).

Germline DNA samples from 98 patients and tumor DNA samples from 28 of them were submitted for whole-exome sequencing (WES) at the University of Minnesota Genomics Center. Targeted capture libraries

Published by Bioscientifica Ltd.

Published by Bioscientifica Ltd. 
were generated using the Agilent QXT v5+UTRs kit for both germline and tumor samples. The germline samples were sequenced on an Illumina HiSeq 2000 platform producing $100 \mathrm{bp}$ paired-end reads, while the tumor samples were sequenced on a HiSeq 2500 platform producing $125 \mathrm{bp}$ paired-end reads. FASTQ files were processed using the steps delineated in the Broad Institute's Genome Analysis Toolkit (GATK) best practices (Van der Auwera et al. 2013), including using BWA-MEM (Li \& Durbin 2010) for alignment, GATK for quality recalibration and indel realignment and GATK HaplotypeCaller for genotyping. The median number of on-target reads generated per sample was 41 million, resulting in median target coverage of $54 \times(78 \%$ of targets covered at $>20 \times$ ). For CABLES1, the median percent of the 10 coding exons covered at $20 \times$ was $100 \%$ (average $=91 \%$ ). The only exon with reduced coverage was exon 1, with $43 \%$ of samples having $20 \times$ coverage. ANNOVAR (Wang et al. 2010a) was used to determine the effect of coding variants using both the RefSeq and UCSC gene sets, including putative amino acid changes, distance to intron-exon boundary, the creation or removal of a stop-codon and location within known non-coding RNAs. Nonsynonymous variants were annotated based on their computationally predicted deleteriousness using information from dbNSFP. All variants were annotated for their frequency and presence in multiple variant collections (e.g., dbSNP, 1000 Genomes and internal WES datasets totaling over 10,000 samples). Targeted bioinformatic analysis ruled out rare mutations (present in $<1 \%$ of any variant collection) in other known pituitary adenoma-associated genes (AIP, CDKN1B, GPR101, MEN1 and PRKAR1A). For all the samples, a manual check of the WES raw data for CABLES1 was performed, using the Integrative Genomics Viewer 2.3.72 platform (Broad Institute) (Robinson et al. 2011).

In addition, 48 other patients were screened for germline CABLES1 variants by Sanger sequencing. The primers included in Supplementary Table 1 (see section on supplementary data given at the end of this article) were used to amplify the coding regions and exon-intron junctions by PCR (GoTaq Green Master Mix, Promega M7123) and for Sanger sequencing (BigDye Terminator 3.1 Cycle Sequencing Kit, Thermo Fisher Scientific 4337456). Sequences were analyzed using the SeqMan Pro 11.1.0 (DNASTAR) software. The Alamut Visual 2.9 software (Interactive Biosoftware) was used for the annotation, in silico prediction and to search the frequency in public databases of all the variants identified. Four algorithms (Align GVGD, PolyPhen-2, SIFT and Mutation Taster) were used for missense variants and five (Splice Site Finder, MaxEnt, NNSplice, GeneSplicer and Human Site Finder) were used for splicing variants. Variants were considered probably damaging or affecting splicing when the majority of the algorithms agreed; otherwise, they were considered variants of uncertain significance (VUS). Sanger sequencing confirmed all the variants identified by WES. Parents of the patients with CABLES1 variants of interest were screened ad hoc, and loss of heterozygosity (LOH) was investigated in the corticotropinomas by Sanger sequencing.

\section{Collection of corticotropinomas from adult patients}

Fresh frozen corticotropinoma tissue samples were obtained from 35 adult patients from Cochin Hospital and Foch Hospital operated for CD between 2009 and 2016. The local ethical committee approved the study, and all the patients provided written informed consent. RNA was extracted using the RNeasy kit (QIAGEN), and then reverse-transcribed. All the samples were submitted for RNA sequencing (RNA-seq) at the genomic platform of Cochin Institute. The libraries were prepared following the TruSeq mRNA protocol (Illumina RS-122-2101), starting from $1 \mu \mathrm{g}$ of high-quality total RNA. Paired-end $(2 \times 75 \mathrm{bp})$ sequencing was performed in an Illumina NextSeq 500 instrument. Reads were aligned using the STAR software (Dobin \& Gingeras 2015). Sequencing variants were annotated using ANNOVAR (Wang et al. $2010 a$ ) and then filtered for exonic nonsynonymous variants, with frequency $<1 \%$ in the general population (based on the 1000 Genomes database) (1000 Genomes Project Consortium et al. 2015). Variants of interest were confirmed by Sanger sequencing in DNA extracted from representative sections of paraffin-embedded tissues, as described previously.

\section{Copy number variation analysis}

CNV analysis was performed in 116 germline and 29 corticotropinoma DNA samples using FAM-labeled assays binding CABLES1 exon 1, intron 3-exon 4 and exon 10 (TaqMan CNV assays Hs07536236_cn, Hs02003953_cn, and Hs00413958_cn, respectively, Thermo Fisher Scientific) a VIC-labeled RPP3O (Rnase P) assay (Thermo Fisher Scientific 4403326) as an internal control, and the ddPCR SuperMix for Probes (no dUTP) (Bio-Rad 1863024) in a QX200 Droplet Digital PCR System (Bio-Rad). Results were analyzed with the Quanta Soft software 1.7.4.0917 (Bio-Rad).

Published by Bioscientifica Ltc. 


\section{USP8 screening}

For patients with potentially pathogenic CABLES1 variants, the primers 5'-CTTCCACCCCTCCAACTCAT-3' and 5'-TGGAGTTACTGTTGGCTTCCT-3' were used to amplify and sequence a region of $146 \mathrm{bp}$ covering the USP8 mutational hotspot in corticotropinoma DNA, as described above. Patients with USP8 mutations from our cohort have been reported elsewhere (Pérez-Rivas et al. 2015, Faucz et al. 2017).

\section{Immunohistochemistry}

In corticotropinomas from patients with putative CABLES1 mutations and in two corticotropinomas with no mutations, immunohistochemical staining for ACTH (1:1000 rabbit polyclonal anti-ACTH antibody, Abcam 74976), CABLES1 (1:1000 rabbit polyclonal Abcam ab75535) and CDKN1B (1:100 rabbit polyclonal Santa Cruz sc-528) was performed as follows: deparaffinization for $30 \mathrm{~min}$ in Histo-Clear (National Diagnostics HS-200), sequential 5-min washes with 100, 95, 70 and 50\% ethanol, antigen retrieval with citratebased antigen unmasking solution (Vector H3300) for $20 \mathrm{~min}$ in a steamer, blocking for $1 \mathrm{~h}$ with $10 \%$ normal goat serum (Jackson ImmunoResearch Laboratories 005-000-121) in $1 \times \mathrm{PBS} / 0.1 \%$ Triton X-100, incubation with primary antibody overnight at $4^{\circ} \mathrm{C}$, incubation with $1 \% \mathrm{H}_{2} \mathrm{O}_{2}$ for $5 \mathrm{~min}$, and then for $1 \mathrm{~h}$ with 1:1000 Biotin-SP AffiniPure Goat Anti-rabbit IgG and for 30 min with 1:500 Peroxidase Streptavidin (Jackson ImmunoResearch Laboratories 111-065-144 and 016030-084, respectively). Samples were developed by incubation for $1 \mathrm{~min}$ with ImmPACT DAB peroxidase (HRP) substrate (Vector SK-4105) and counterstained with Gill's hematoxylin I (American MasterTech Scientific HXGHE1PT) and Dako Bluing Buffer (Agilent Technologies CS70230-2). Sequential washes in a 50-100\% ethanol gradient and Histo-Clear were done before mounting with Cytoseal XYL (Thermo Fisher Scientific 8312-4). Images were acquired using a Leica DMRX optical microscope, attached to an Olympus DP72 camera, and processed with the CellSens Dimension 1.6 software (Olympus).

\section{Expression plasmids}

The mouse Cables1 cDNA (variant 1: NM_001146287.1) was obtained from IDT and inserted downstream of the 
tamoxifen-inducible form of the estrogen receptor $\left(\mathrm{ER}_{\mathrm{tam}}\right)$ ligand-binding domain into a 3xFlag-tagged retroviral expression vector derived from pLNCX2 (Littlewood et al. 1995). Mutagenic primerswereused tointroducethe Cables 1 point mutations p.E139K (p.E178K in human, 5'-GCCACGAGTCCTCGGGAAACCCTCACAACCAC-3' and 5'-GTGGTTGTGAGGGTTTCCCGAGGACTCGTGGC-3'), p.L201F (p.L240F in human, 5'-GGGTCAAGGGGTAGATTTAATTCCTTTACTCAGGG-3' and 5'- CCCTGAGTAAAGGAATTAAATCTACCCCTTGACCC-3' ), p.G273D (p.G312D in human, 5'-GTCGAACACTTTCAGATTCTCCTAGACCAAAG-3' and 5'-CTTTGGTCTAGGAGAATCTGAAAGTGTTCGAC-3') and p.D424G (p.D463G in human, 5'-GACCCAAACCTCCTGGGTGACCCCCAGTGGCC-3' and 5'-GGCCACTGGGGGTCACCCAGGAGGTTTGGGTC-3') in the plasmid, using the QuikChange site-directed mutagenesis kit (Agilent Technologies 200519) and the KOD hotstart DNA polymerase (Millipore 71086). The vectors were transfected into EcoPackTM 2-293 cells (Clontech 631506) to produce the viruses, which were then used to transduce AtT-20/ D16v-F2 cells (ATCC CRL-1795).

\section{Cell culture, transfections and growth curves}

The transformed AtT-20/D16v-F2 cells were grown in Dulbecco's modified Eagle medium, supplemented with $10 \%$ fetal bovine serum and antibiotics. Pools of at least $1 \times 10^{3}$ stable cell colonies were obtained as described (Rambaud et al. 2009) for pLNCX2-3xFlag-ER tam -Cables1 WT, pLNCX2-3xFlag-ER tam $^{-C a b l e s 1 ~ p . E 178 K, ~ p L N C X 2-~}$ 3xFlag-ER tam -Cables1 p.L240F, pLNCX2-3xFlag-ER tam $^{-}$ Cables1 p.G312D, pLNCX2-Flag-ER tam $^{-C a b l e s 1 ~ p . D 463 G ~}$

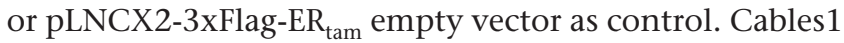
protein levels were assessed by Western blot using $1 \mu \mathrm{g}$ mouse monoclonal anti-Flag (SIGMA F1804) antibody. For growth curves, $7 \times 10^{5}$ cells per well were plated in 6 -well plates and treated in duplicate with $400 \mathrm{nM}$ tamoxifen (SIGMA T5648), 10-7 M dexamethasone (SIGMA D4902), both or vehicle (100\% ethanol). Viable cells were counted every $12-18 \mathrm{~h}$ for 4 days, starting $4 \mathrm{~h}$ after plating, and medium was replaced with fresh medium at every time point.

\section{Statistical analyses}

All the analyses were carried out using the GraphPad Prism 7.0 software (GraphPad Software). Parametric data are presented as mean \pm standard deviation (S.D.) and nonparametric data are presented as median \pm interquartile range (IQR). Gene variant frequencies in the study population were compared with the frequencies reported in public databases using the Fisher's exact test. For the cell growth experiment with WT CABLES1, cell counts at each time point were compared among experimental conditions using one-way ANOVA with Dunnett correction for multiple comparisons. For the rest of the experiments, cell counts at different time points were compared between ethanol and tamoxifen treatments using multiple $t$ tests, with Holm-Sidak correction for multiple comparisons. Results were considered statistically significant when $P<0.05$.

\section{Results}

\section{Genetic findings}

The pediatric CD cohort was composed of 72 males and 74 females, with mean age at first symptoms of $10.3 \pm 3.3$ years and age at diagnosis of $12.5 \pm 3.4$ years, for a median delay between disease onset and diagnosis of 26 months (IQR $12-38.3$ ). The median pituitary tumor size was $4 \mathrm{~mm}$ (IQR $4-7) ; 88.1 \%(126 / 146)$ of the patients had microadenomas and $8.2 \%(12 / 146)$ had macroadenomas. Four patients (2.7\%) had two or more adenomas and in four cases, the tumor was not identified, despite response to surgical treatment in three of them. The first line of treatment was transsphenoidal surgery in all the cases, except for one patient who developed spontaneous apoplexy of the pituitary adenoma. Ninety-seven percent of the patients (141/146) had sporadic presentation; among them, we identified two simplex patients with mutations in AIP and PRKAR1A, as previously reported (Stratakis et al. 2010, Hernández-Ramírez et al. 2017). Out of the five familial cases, three were members of families with a multiple endocrine neoplasia phenotype (two of them with MEN1 mutations) as previously described (Stratakis et al. 2010) and two had a FIPA phenotype (family history of prolactinomas), but tested negative for AIP mutations. None of the patients had a family history of CD.

The adult cohort consisted of $35 \mathrm{CD}$ patients, including 25 females and 10 males. Mean age at diagnosis was 44 years (range: 16-83). A microadenoma was found in $22.9 \%(8 / 35)$ and a macroadenoma in $77.1 \%(27 / 35)$ of the patients. Seventeen patients $(48.6 \%)$ presented with overt $\mathrm{CD}$, whereas clinical signs were limited or absent for the rest of them. 
Four missense CABLES1 single-nucleotide variants of interest (each in one patient) were identified among the 182 patients studied (Table 1), affecting exon 1 (c.532G $>$ A, p.E178K and c.718C $>$ T, p.L240F), exon 3 (c.935G > A, p.G312D) and exon 7 (c.1388A > G, p.D463G), respectively (Fig. 1 and Table 1). These missense variants were selected because of being either novel (p.D463G) or very infrequent in the general population (p.E178K, p.G312D) and/or because they were predicted to affect the protein structure (p.L240F, p.D463G). The ExAC database reported a frequency of $2.8 \%$ for the p.E178K variant: this might be an overestimation, since coverage for CABLES1 exon 1 was low in the ExAC and gnomAD databases (Lek et al. 2016), while the 1000 Genomes database reported a much lower frequency. No pathogenic associations were reported for these variants in ClinVar or The Human Gene Mutation Database (Stenson et al. 2003, Landrum et al. 2016).

In addition, other CABLES1 variants (five of them not previously reported in public databases) were identified

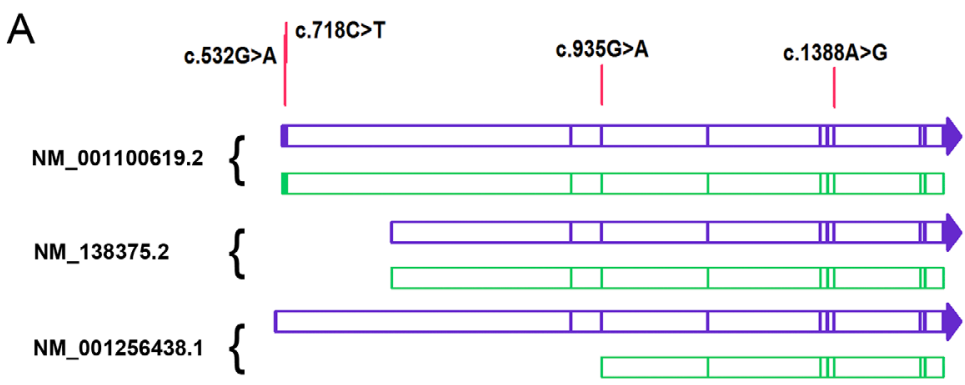

B

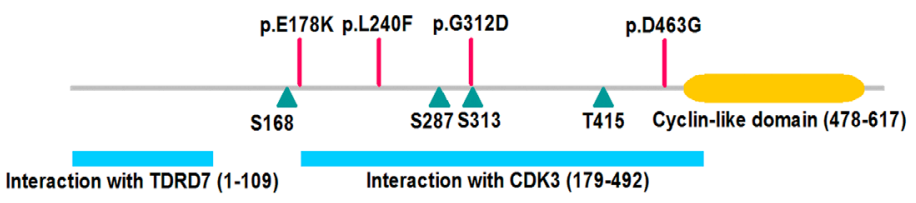

C

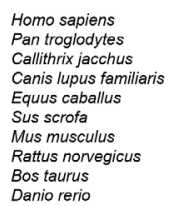
Bos taurus
Danio rerio

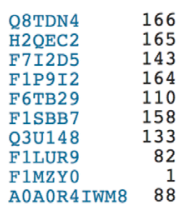

\section{p.E178K}

FASPLGAGRASGERQPPRPAPLAACAQLQLIDG

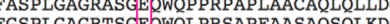
FTSPLGAGRASGEOPOPPRPAPPASCAPPOLPD FSSSLGAGRASGEQWPLPRPAPIAACAOPOOPDG -------PRASGEQLOLPRPALLAACGOPOLPNG ------VPRVLE PSQPPRSAPAVTGAQLQLPDG ------VPRVLGEPSQPPRSAPAVIGQLQLPDG FMAGTVATSA-- AAAAPPPPD----------PDG

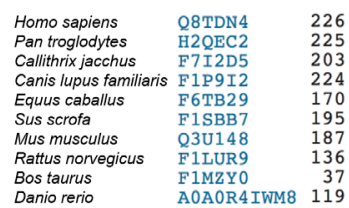

p.L240F

GSGTPGSGSGSRGRINSFTQGILPIAFSRPTSON SGTPGSGSGSRGRINSFTQGILPIAFSRPTSO GSGTPGSGSGSRGRLNSFTQGILPIAFSRPTSQ GSGTPGSGGGSRSRINSFTOGILPIAFSROTSON ------------xNSFTOGILPIAFSROTSO GSGTPGSTSGSRGRUNSFTOGILPIAFSRONSO GSGTPGSASGSRGRINSFTQGILPIAFSRQNSO SSGTPGGGSGSRGRINSFTQGILPIAFSRQTSON SSPF SAVPPATRGRIQTYTQGILPVSYARQSSQN Pan troglodyles T2OEC2 Canis lupus familiaris F1P9I2 Equus caballus Mus musculus Rattus norvegicus Bos taurus
Danio rerio
p.G312D

\begin{tabular}{|c|c|c|c|}
\hline \multicolumn{4}{|c|}{ p.D463G } \\
\hline & & & \\
\hline & & & \\
\hline & $\begin{array}{l}\text { F7I2D5 } \\
\text { F7p9I2 }\end{array}$ & $\begin{array}{l}440 \\
461\end{array}$ & FGKHKRVLIFPSYMTTVIDY \\
\hline & F6TB29 & $\begin{array}{l}461 \\
407\end{array}$ & GKRVLIF \\
\hline & F1SBB7 & 418 & NPCGHKRVLIFPSYMTTVIDYVKPSDLKK \\
\hline Ius & $\begin{array}{l}\text { Q3U148 } \\
\text { F1LUR9 }\end{array}$ & 424 & WFCGKHKRVLTFPSYMTTVIDYVYKPSDLKK \\
\hline & FILUR9 & 248 & 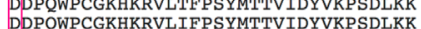 \\
\hline & & 355 & NPCGKHKRVLIF PSYMTTVIEYVKPSDLK \\
\hline
\end{tabular}

\section{Figure 1}

Missense CABLES1 variants of interest: effects on CABLES1 transcripts and proteins. (A) Three transcripts of CABLES1, NM_001100619.2, NM_138375.2 and NM_001256438.1, which differ in their first exon, are translated into proteins of 633, 368 and 306 amino acids, respectively. The former (NM_001100619.2,) is the 'canonical' sequence (UniProt Q8TDN4-1). For each transcript, mRNA is schematized in blue and the coding sequence in green. The CABLES1 variants identified in Patients 1 and 2 (p.E178K and p.L240F), respectively, affect exon 1 of the reference transcript, but not the other transcripts. The variant detected in Patient 3 is located in exon 3 (p.G312D) and the variant from Patient 4 (p.D463G) affects exon 7. There is no information in the literature about the expression of these transcripts in the pituitary gland. (B) The domains of the CABLES1 protein are incompletely characterized and no 3-D structure is available that represents the majority of the protein sequence. The 633 amino acid (65.7 kDa) isoform of the protein contains an N-terminal site for interaction with TDRD7 and a central large sequence necessary for interacting with CDK3. Four residues are targets for phosphorylation: S168, S287, S313 and T415 (Shi et al. 2015, Uniprot Consortium 2015, Yamochi et al. 2001). The C-terminal end of the protein contains a cyclin-like domain, and for this reason, CABLES1 has been included in the cyclin superfamily, although it differs in functions with cyclins. The alterations found in Patients 1-4 are included in (p.L240F, p.G312D, p.D463G) or very close to (p.E178K) the motif that interacts with CDK3. (C) The CABLES1 gene is highly conserved among species, and the variants found in our patients affect relatively (p.E178K, p.L240F) and highly (p.G312D, p.D463G) conserved residues. 
in the pediatric cohort (Supplementary Table 2). Given the methods used for screening, we could not accurately assess the frequency of intronic variants. No CNVs were found in the samples analyzed by ddPCR.

\section{Clinical, genetic and histopathological features in patients with putative CABLES1 mutations}

We identified putative CABLES1 mutations in four sporadic female patients: two young adults (Table 2, cases 1 and 2) and two pediatric cases (cases 3 and 4). All these putative mutations were found in the heterozygous state in the germline DNA samples, and no $\mathrm{LOH}$ was detected in the pituitary adenomas. The four tumor samples were negative for USP8 hotspot mutations. All these patients had large corticotropinomas (3/4 with extrasellar extension) with high Ki-67 proliferation index, and three of them required a second transsphenoidal surgery (and radiotherapy in one case) to achieve disease control.

Patient 1 presented at age 27 years with clinical manifestations due to the mass effect of her tumor (macroadenoma extending to the sphenoid and cavernous sinuses). She was diagnosed with a clinically nonfunctioning pituitary adenoma and two transsphenoidal surgeries followed by radiotherapy, were required to achieve control. Histopathological analysis established the diagnosis of a silent corticotroph adenoma, with microscopic invasion of the dura mater, bone and respiratory mucosa, Ki-67 index of $6 \%$ and 2 mitoses per 10 high-power fields.

Patient 2 presented with a clinical phenotype consistent with hypercortisolemia and was diagnosed with $\mathrm{CD}$ at age 32 years. Her pituitary macroadenoma with parasellar extension to the cavernous sinus was surgically removed. The resected tumor had a Ki-67 index of $8 \%$ and 7 mitoses per 10 high-power fields, but invasion of surrounding structures could not be assessed in the specimen. Since the patient was lost to follow-up, we have no data of her current status.

Patient 3 was diagnosed with CD at age 16 years, after a one-year history of hypertension, Cushingoid features and weight gain (weight: $131.4 \mathrm{~kg}$, height: $160 \mathrm{~cm}$, BMI: $\left.51.3 \mathrm{~kg} / \mathrm{m}^{2}\right)$. She had elevated midnight cortisol $(24.6 \mu \mathrm{g} /$ $\mathrm{dL}$ ), and urinary free cortisol (UFC, $437 \mu \mathrm{g} / \mathrm{dL}, \times 11$ ULN), unsuppressed serum cortisol $(20.6 \mu \mathrm{g} / \mathrm{dL})$ after a low-dose dexamethasone suppression test (LDDST) and her ACTH doubled during a CRH stimulation test (55.3-113 pg/mL). Her macroadenoma with suprasellar extension was resected, but a 15 -month remission period was followed by recurrence, requiring a second surgery
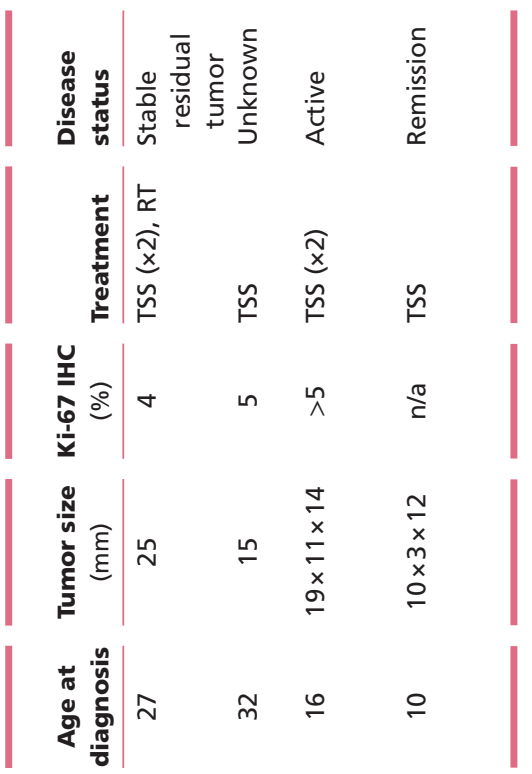

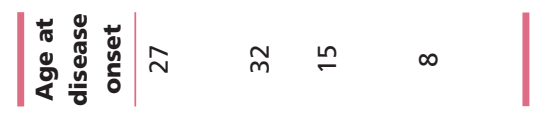

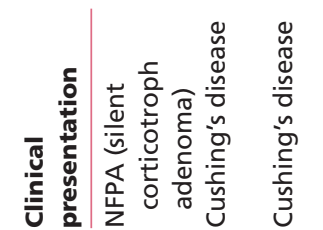

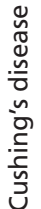

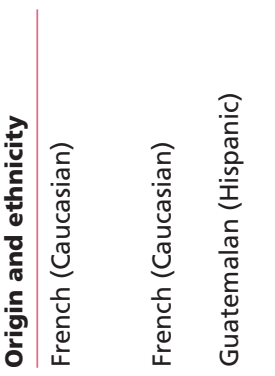

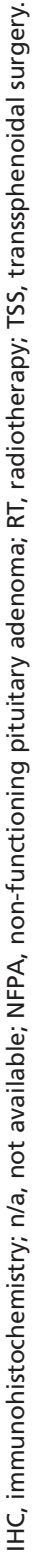

Published by Bioscientifica Ltd. 
and remaining hypercortisolemic afterward. Genetic screening identified paternal inheritance of her putative CABLES1 mutation, but despite being a carrier, her father was apparently unaffected.

Patient 4 had a congenital polycystic non-functional kidney, and her family history included one case of gastric cancer. She was evaluated at age 10 2/12 years because of decreased growth velocity (height $132 \mathrm{~cm},-1$ S.D.), hypertension, hirsutism and Cushingoid features, which developed in the previous 26 months. She had elevated ACTH $(19.1 \mathrm{pg} / \mathrm{mL})$ and midnight cortisol $(19 \mu \mathrm{g} /$ $\mathrm{dL}$ ), failed a LDDST (cortisol $17 \mu \mathrm{g} / \mathrm{dL}$ ) and had central hypothyroidism and dyslipidemia. Bilateral petrosal sinus sampling under CRH stimulation resulted in 3:1 central to peripheral ACTH ratio, confirming CD. Her pituitary adenoma without extrasellar extension was successfully resected, and the patient achieved remission. The CABLES1 alteration found in the patient was absent in her mother's DNA. As a sample from the father was not available, we cannot determine whether the variant was inherited or appeared de novo.

Compared with samples without CABLES1 alterations, samples from Patients 1 to 4 displayed reduced CDKN1B cytoplasmic and, more importantly, nuclear expression by immunohistochemistry (Fig. 2). No differences were found in the CABLES1 staining between samples with and without putative CABLES1 mutations, although it was weaker in the tumors than in areas of non-tumoral pituitary (data not shown). This finding was not unexpected, as none of the samples displayed LOH for the variants identified, and points toward an alternative mechanism for reduced CABLES1 activity in the corticotroph cells.

\section{Functional assessment of putative CABLES1 mutations}

The conditional tamoxifen-inducible chimeric $\mathrm{ER}_{\mathrm{tam}}{ }^{-}$ CABLES1 proteins inserted by retroviral transduction were expressed at similar levels among the different AtT20/D16v-F2 cell pools (Fig. 3A). As expected (RousselGervais et al. 2016), WT CABLES1 inhibited the growth of AtT-20/D16v-F2 cells, but not as much as treatment with the synthetic glucocorticoid dexamethasone $\left(10^{-7} \mathrm{M}\right)$ or their combination (Fig. 3B). This result was expected, as AtT-20/D16v-F2 cells express CABLES1 in response to dexamethasone, but CABLES1 is only one of a group of dexamethasone-controlled cell cycle regulators (RousselGervais et al. 2016). In contrast, p.E178K (Fig. 3C), p.L240F (Fig. 3D), p.G312D (Fig. 3E) and p.D463G (Fig. 3F) CABLES1 mutants lost the ability to inhibit
AtT-20/D16v-F2 cell growth. In summary, all the CABLES1 variants identified in our patients affect a core property of CABLES1: its ability to inhibit cell growth in response to glucocorticoids.

\section{Discussion}

The CABLES1 gene has been recently identified as a key mediator of the regulatory feedback loop of glucocorticoids on the corticotroph cells (Roussel-Gervais et al. 2016). We have identified a small, but not negligible number $(2.2 \%$, 4/181) of patients with CABLES1 alterations. The four putative mutations identified in our patients displayed reduced ability to block corticotroph cell proliferation in response to dexamethasone stimulation, supporting a role for CABLES1 as a regulator of the corticotroph cell growth. Ours is the first study to identify a human phenotype associated with CABLES1 germline mutations.

The CABLES1 protein was originally described as an interacting partner and substrate of the cyclin-dependent kinase-3 (CDK3) (Matsuoka et al. 2000, Yamochi et al. 2001). It plays an important role in neural development during embryogenesis, as inferred from in vitro studies and from the mouse and zebrafish models of gene inactivation (Zukerberg et al. 2000, Groeneweg et al. 2011, Mizuno et al. 2014). CABLES1 is highly expressed in the nucleus of proliferating cells, where it is tightly regulated throughout the cell cycle, peaking at mid-late G1 (Matsuoka et al. 2000, Wu et al. 2001, Yamochi et al. 2001). In addition to CDK3, CABLES1 is a substrate for other protein kinases, including CDK2, 14-3-3, AKT, CDK5 and ABL, also serving as an adaptor protein for the last two (Zukerberg et al. 2000, Wu et al. 2001, Shi et al. 2015b). Another important function of this protein is to stabilize regulators of the cell cycle, such as CDKN1A (P21), CDK5R1 (P35) and TP63, preventing their degradation (Zukerberg et al. 2000, Wang et al. 2010b, Groeneweg et al. 2011, Shi et al. 2015a). CABLES1 also interacts with TP53 and TP73, triggering apoptosis (Tsuji et al. 2002).

The CABLES1 protein is widely expressed among tissues and is lost in a variety of human cancers (endometrial, ovarian, colorectal, lung and squamous cell carcinomas) (Kirley et al. 2005a). CABLES1 gene inactivation promotes cell proliferation and survival, as well as tumor formation in vitro and replicates the human neoplasms in mouse models (Wu et al. 2001, Dong et al. 2003, Zukerberg et al. 2004, Kirley et al. 2005a,b). The tumor suppressor activity of CABLES1 is inhibited by 14-3-3 or AKT-mediated phosphorylation (Shi et al. 2015b). 


(2)
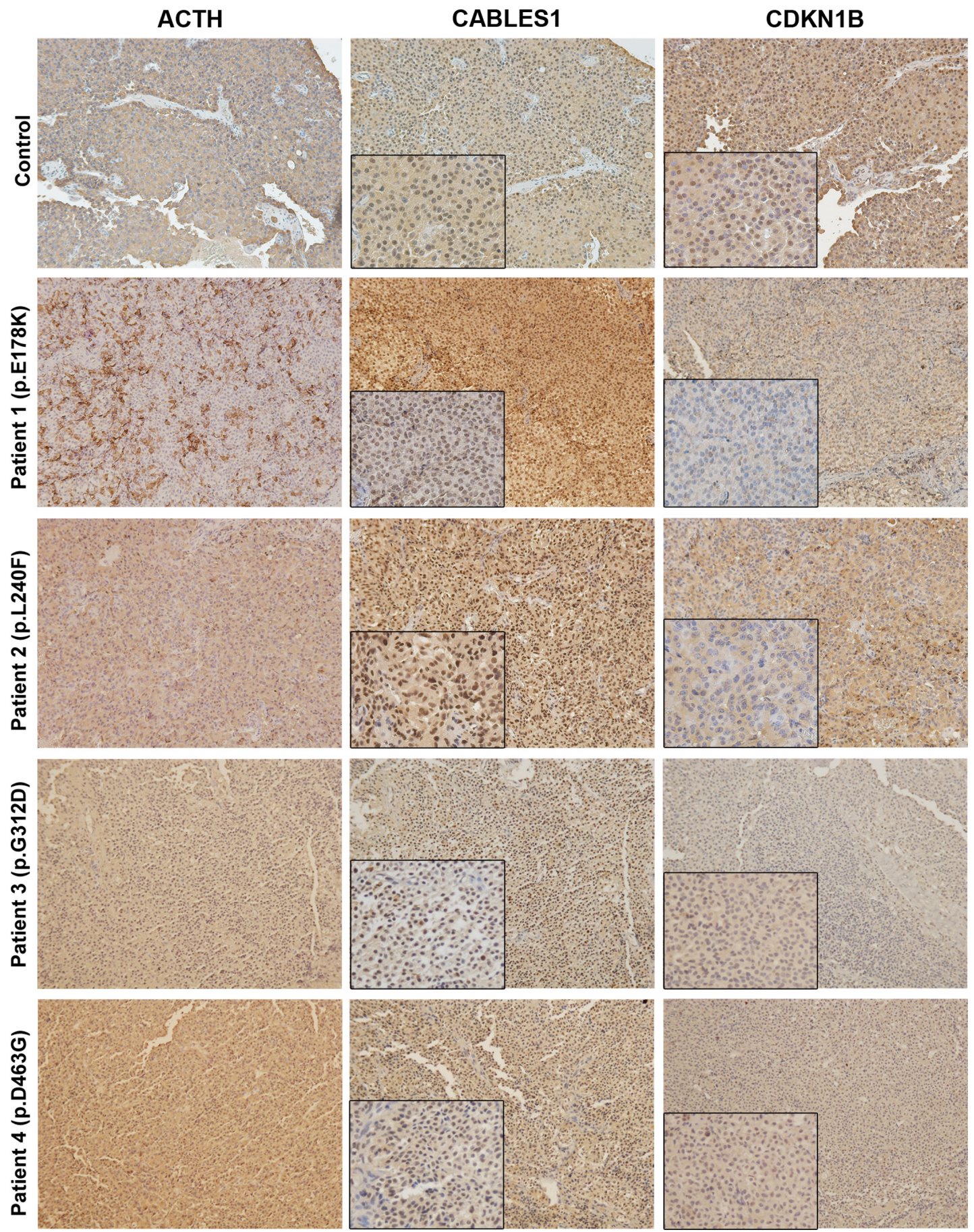

\section{Figure 2}

ACTH, CABLES1 and CDKN1B expression in corticotropinomas. We compared ACTH, CABLES1 and CDKN1B immunostaining in samples from the four patients with putative CABLES1 mutations with samples from two patients negative for such alterations (one representative example is presented). ACTH immunostaining was observed in the vast majority of the cells in all the cases, except for Patient 1, for whom only $50 \%$ of the cells were immunoreactive (immunoreactivity for other pituitary hormones was ruled out). All the samples displayed positive CABLES1 cytoplasmic and, predominantly, nuclear immunoreactivity. In specimens that contained areas of non-tumoral pituitary, reduced CABLES1 staining was observed in the corticotropinomas, compared with the surrounding tissue (Supplementary Fig. 1), in concordance with previous data (Roussel-Gervais et al. 2016).

Nevertheless, we did not observe differences in the CABLES1 immunostaining between samples with and without putative CABLES1 mutations. In contrast, while in controls CDKN1B staining was moderately intense in the cytoplasm of the great majority of the cells and in the nucleus of 50-60\% of them, only weak cytoplasmic staining and very few cells with nuclear staining were observed in the cases with putative CABLES1 mutations ( $<10 \%$ cells with nuclear staining for Patients 1 and 2 and 30-40\% cells with weak nuclear staining for Patients 3 and 4). Magnification in all the images: 10x, inserts: 20x. 
A

\section{3xFlag $\mathrm{ER}_{\text {tam }}$ Cables1}

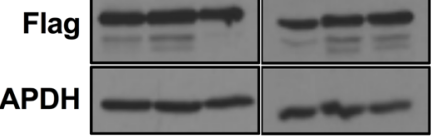

C

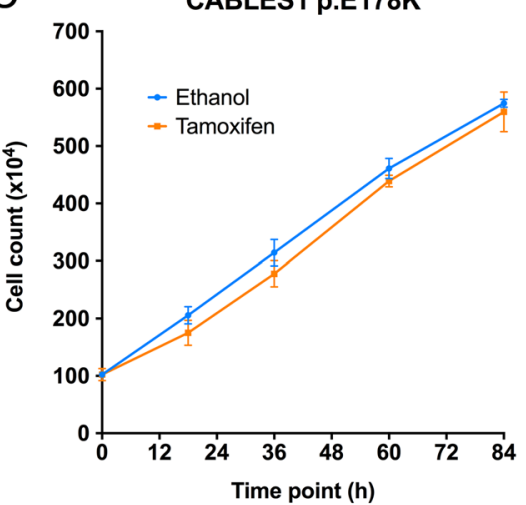

E

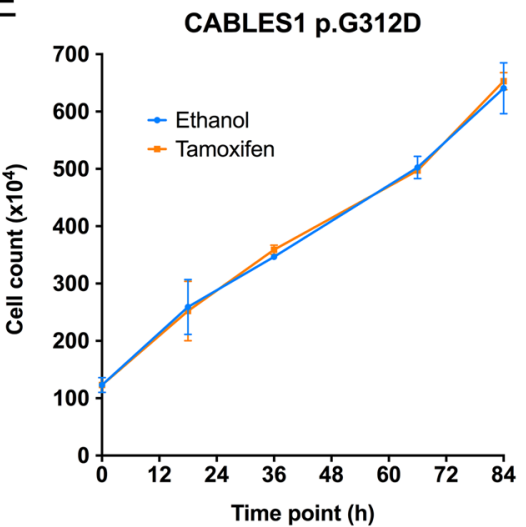

B
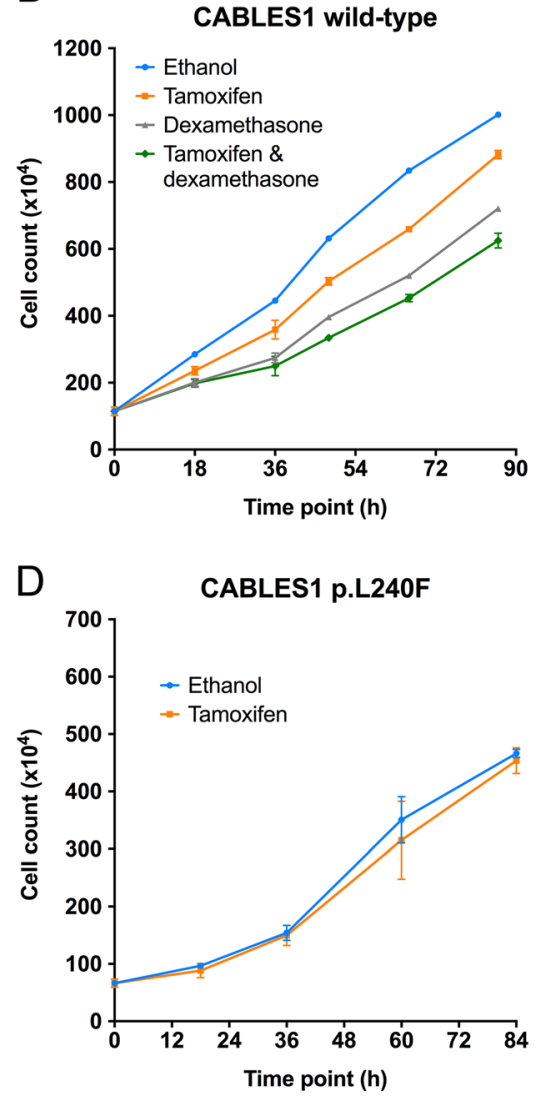

F

CABLES1 p.D463G

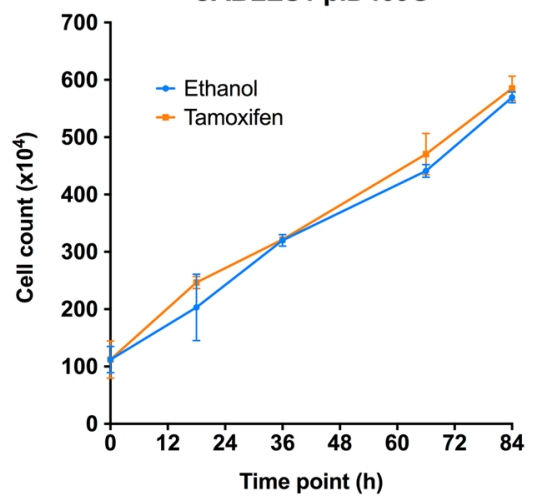

Figure 3

CABLES1 mutant proteins have lost their growth inhibition activity. (A) Schematic representation of tamoxifen-inducible chimeric CABLES1 proteins fused to the $\mathrm{ER}_{\text {tam }}$ ligand-binding domain. Upon stable transduction of AtT-20 cells, wild-type (WT) and mutant $\mathrm{ER}_{\mathrm{tam}}$-CABLES1 proteins are expressed at similar levels as revealed by Western blot against the Flag epitope. (B) Growth curves of AtT20/D16v-F2 cells expressing WT ER tam $_{\text {-CABLES1 }}$ treated with vehicle (ethanol), tamoxifen, dexamethasone or both, as indicated. All the conditions rendered statistically significant differences in cell counts at all time points. To analyze exclusively the effect of CABLES1 on cell growth, only the tamoxifen treatment was used for experiments with the mutant proteins. (C, D, E and F) Growth curves for AtT20/D16v-F2 cells expressing CABLES1 p.E178K (C), p.L240F (D), p.G312D (E) or p.D463G (F) mutant protein in vehicle and tamoxifen-treated cells. There were no statistically significant differences in cell count at the different time points, meaning that these variants have lost the ability to suppress cell growth.
Interestingly, CABLES1 could provide a link between two important molecular mechanisms disrupted in corticotropinomas: dysfunction of the CDK/cyclin-dependent cell cycle regulation and activation of the epidermal growth factor receptor (EGFR) pathway (Fukuoka et al. 2011, Liu et al. 2011a,b). The RAC-alpha serine/threonine-protein kinase (AKT1), one of the main effectors of EGFR, can inactivate CABLES1 by phosphorylation, neutralizing this way the regulatory effect of CABLES1 over the CDK/cyclin complexes (Fukuoka et al. 2011, Shi et al. 2015b).
Although a characteristic phenotype cannot be inferred from such a small number of patients, we found some noteworthy features. The four patients had youngonset macroadenomas, in agreement with previous observations suggesting that germline mutations in pituitary adenoma-causative genes are relatively frequent among patients with such characteristics (Stratakis et al. 2010, Tichomirowa et al. 2011). The tumors in the two adults were particularly large and aggressive, suggesting that, perhaps, they had arisen years before their diagnoses. 
Considering that our patients had sporadic disease presentation, and given that corticotropinomas rarely remain asymptomatic over time, we could assume an incomplete penetrance for CABLES1-associated CD, which could explain the low frequency of these cases. Along these lines, it is important to emphasize that incomplete penetrance is a frequent finding among kindreds with pituitary adenoma-associated germline alterations (Williams et al. 2014, Iacovazzo et al. 2017). The study of large pedigrees with multiple cases of CD might be necessary to identify additional cases. However, the finding of multiple patients with CD in the same family is quite an infrequent phenotype: only $7.9 \%$ of the AIP mutationnegative FIPA families include $\mathrm{CD}$, and only $1.4 \%$ of the families are 'homogeneous' for corticotropinomas (Hernández-Ramírez et al. 2015). On the other hand, as we could not establish the pattern of inheritance in three of the cases, de novo mutations cannot be confirmed or ruled out. A caveat of our study is that we could not rule out that the CABLES1 mutations found in the adult patients were somatic defects, as germline DNA samples were not available from these cases. It is however noteworthy that the father of Patient 3 carries the CABLES1 mutation: this may suggest that CABLES1 mutations may predispose to $\mathrm{CD}$ and potentially be associated with very rare cases of familial CD, with incomplete penetrance.

Another interesting feature is the absence of somatic USP8 mutations in our patients. This is the most common genetic defect so far identified in corticotropinomas, being found in around $40 \%$ of the tumors (PérezRivas et al. 2015, Reincke et al. 2015). We have recently identified such mutations in one-third of our pediatric CD patients (Faucz et al. 2017). The absence of this somatic defect somehow mirrors the absence of GNAS1 mutations in patients with somatotropinomas due to AIP mutations, suggesting that the genetic defects causing tumors due to germline predisposition are different than those found in non-inherited pituitary adenomas (HernándezRamírez et al. 2015).

The histopathological analysis of the samples revealed other common features among the four cases. CABLES1 expression ranged from low to moderate, but it was not completely absent in any of the tumors and was predominantly nuclear. However, the nuclear CDKN1B (P27) staining was particularly affected, compared with other corticotropinomas. Human germline CDKN1B mutations are associated with approximately $2 \%$ of the cases of MEN1 mutation-negative multiple endocrine neoplasia (Georgitsi et al. 2007). Cases associated with CDKN1B mutations display a heterogeneous phenotype, referred to as MEN4, encompassing parathyroid and pituitary adenomas, neuroendocrine tumors and various benign and malignant tumors (Pellegata et al. 2006). Pituitary tumors have been reported in nine MEN4 patients so far, only one of them with CD (Agarwal et al. 2009, Lee \& Pellegata 2013, Sambugaro et al. 2015). However, Cdkn1b-knockout (KO) mice develop, among other phenotypic abnormalities, ACTH-secreting hyperplasia or adenomas of the pituitary pars intermedia with full penetrance (Fero et al. 1996, Kiyokawa et al. 1996, Nakayama et al. 1996).

More importantly, nuclear CDKN1B immunostaining is significantly reduced in pituitary adenomas of all types, particularly in corticotropinomas, in association with high Ki-67 expression, and is lost in pituitary carcinomas (Lidhar et al. 1999, Korbonits et al. 2002). This low expression is very likely not due to mutations or deletions, since these alterations have not been detected at the somatic level, but caused by posttranslational events (Dahia et al. 1998). The bestcharacterized mechanism for this in CD is increased CDKN1B phosphorylation by cyclin E (upregulated in corticotropinomas), which inactivates the protein and triggers its degradation, although 14-3-3 and AKT-mediated phosphorylation have the same effect (Korbonits et al. 2002, Susaki \& Nakayama 2007, Roussel-Gervais et al. 2010). We observed that CDKN1B nuclear expression was particularly low in tumors with putative CABLES1 mutations. As CABLES1 is known to stabilize and prevent the degradation of other cyclindependent kinases, we could speculate that our findings are due to increased CDKN1B degradation as a result of impaired CABLES1 function. This is in agreement with the rough correlation between CABLES1 and CDKN1B, but not cyclin $\mathrm{E}$ expression by immunohistochemistry in CD patients (Roussel-Gervais et al. 2016). Further experiments are required to confirm this mechanism, although they are beyond the scope of the present article.

We acknowledge the limitations of our study. Given that our centers are tertiary referral hospitals, aggressive or atypical cases of $\mathrm{CD}$ might be overrepresented in our cohorts. Although only a minority of the patients had macroadenomas, the frequency was higher than what is reported in the literature (Storr et al. 2011). The adult CD cohort included only patients for whom tissue was available, which means macroadenomas would be overrepresented. While these selection biases might preclude any inference on the prevalence of CABLES1 variants in the general population of patients with $C D$, it was probably the uniqueness of our cases, which allowed

Published by Bioscientifica Ltd 
us to identify such uncommon genetic alterations. Also, we do not have a firm basis to explain why the loss of function of a 'generic' tumor suppressor such as CABLES1 caused a pituitary-specific phenotype in our patients. We could speculate that the missense variants found in these cases might cause loss of crucial pituitary-specific proteinprotein interactions, but further studies are required to better characterize the function of this tumor suppressor in the corticotroph cells.

Our results provide evidence for a role of CABLES1 as a novel pituitary tumor suppressor. The function of the CABLES1 protein as a regulator of different elements of the molecular pathways that control the cell cycle progression and apoptosis links genes previously known to have a role in the pathogenesis of $\mathrm{CD}$. A more detailed characterization of such regulatory networks will allow a better understanding of the genetic basis of corticotropinomas, providing grounds for the search of novel therapeutic targets.

\section{Conclusions}

We have identified four potentially pathogenic missense CABLES1 variants as a novel, although infrequent, cause of CD in children and young adults. The CABLES1 protein functions as a glucocorticoid-responsive regulator of the effect of growth factor receptor activation on cell cycle control in the corticotroph cells. The putative CABLES1 mutations found in our patients impair the ability of this tumor suppressor to control cell proliferation and might influence the function of CDKN1B by regulating its subcellular localization and/or degradation. Further studies are required to characterize in detail the function of this tumor suppressor in the corticotroph cells.

\section{Supplementary data}

This is linked to the online version of the paper at http://dx.doi.org/10.1530/ ERC-17-0131

\section{Declaration of interest}

The authors declare that there is no conflict of interest that could be perceived as prejudicing the impartiality of this article.

\section{Funding}

This work was supported by the Intramural Research Program, NICHD, NIH (DIR and DIPHR, NICHD and contract HHSN275201300023I), grants from the Canadian Institutes of Health Research (R G, A N, Y G and J D) and by the Fondation Foch (Foch Hospital, Suresnes, France) (C V).

\section{Acknowledgements}

The authors thank Franck Letourneur from the genomic platform of Cochin Institute, and Victoria Verjus, Clinical Research Nurse from the Unité de Recherche Clinique et Centre d'Investigation Clinique, Paris Descartes University (Necker, Cochin).

\section{References}

1000 Genomes Project Consortium; Auton A, Brooks LD, Durbin RM, Garrison EP, Kang HM, Korbel JO, Marchini JL, McCarthy S, McVean GA, et al. 2015 A global reference for human genetic variation. Nature 526 68-74. (doi:10.1038/nature15393)

Agarwal SK, Mateo CM \& Marx SJ 2009 Rare germline mutations in cyclin-dependent kinase inhibitor genes in multiple endocrine neoplasia type 1 and related states. Journal of Clinical Endocrinology and Metabolism 94 1826-1834. (doi:10.1210/jc.2008-2083)

Caimari F \& Korbonits M 2016 Novel genetic causes of pituitary adenomas. Clinical Cancer Research 22 5030-5042. (doi:10.1158/10780432.CCR-16-0452)

Cazabat L, Bouligand J, Salenave S, Bernier M, Gaillard S, Parker F, Young J, Guiochon-Mantel A \& Chanson P 2012 Germline AIP mutations in apparently sporadic pituitary adenomas: prevalence in a prospective single-center cohort of 443 patients. Journal of Clinical Endocrinology and Metabolism 97 E663-E670. (doi:10.1210/jc.20112291)

Dahia PL, Aguiar RC, Honegger J, Fahlbush R, Jordan S, Lowe DG, Lu X, Clayton RN, Besser GM \& Grossman AB 1998 Mutation and expression analysis of the $p 27 / k i p 1$ gene in corticotrophin-secreting tumours. Oncogene 16 69-76. (doi:10.1038/sj.onc.1201516)

Dobin A \& Gingeras TR 2015 Mapping RNA-seq reads with STAR. Current Protocols in Bioinformatics 51 11.14.1-19. (doi:10.1002/0471250953.bi1114s51)

Dong Q, Kirley S, Rueda B, Zhao C, Zukerberg L \& Oliva E 2003 Loss of cables, a novel gene on chromosome 18q, in ovarian cancer. Modern Pathology 16 863-868. (doi:10.1097/01.MP.0000084434.88269.0A)

Faucz FR, Tirosh A, Tatsi C, Berthon A, Hernández-Ramírez LC, Settas N, Angelousi A, Correa R, Papadakis GZ, Chittiboina P, et al. 2017 Somatic USP8 gene mutations are a common cause of pediatric Cushing disease. Journal of Clinical Endocrinology and Metabolism (in press). (doi:10.1210/jc.2017-00161)

Fero ML, Rivkin M, Tasch M, Porter P, Carow CE, Firpo E, Polyak K, Tsai LH, Broudy V, Perlmutter RM, et al. 1996 A syndrome of multiorgan hyperplasia with features of gigantism, tumorigenesis, and female sterility in p27(Kip1)-deficient mice. Cell 85 733-744. (doi:10.1016/ S0092-8674(00)81239-8)

Fukuoka H, Cooper O, Ben-Shlomo A, Mamelak A, Ren SG, Bruyette D \& Melmed S 2011 EGFR as a therapeutic target for human, canine, and mouse ACTH-secreting pituitary adenomas. Journal of Clinical Investigation 121 4712-4721. (doi:10.1172/JCI60417)

Georgitsi M, Raitila A, Karhu A, van der Luijt RB, Aalfs CM, Sane T, Vierimaa O, Makinen MJ, Tuppurainen K, Paschke R, et al. 2007 Germline CDKN1B/p27Kip1 mutation in multiple endocrine neoplasia. Journal of Clinical Endocrinology and Metabolism 92 3321-3325. (doi:10.1210/jc.2006-2843)

Groeneweg JW, White YA, Kokel D, Peterson RT, Zukerberg LR, Berin I, Rueda BR \& Wood AW 2011 cables1 is required for embryonic neural development: molecular, cellular, and behavioral evidence from the zebrafish. Molecular Reproduction and Development 78 22-32. (doi:10.1002/mrd.21263)

Hernández-Ramírez LC, Gabrovska P, Denes J, Stals K, Trivellin G, Tilley D, Ferrau F, Evanson J, Ellard S, Grossman AB, et al. 2015 Landscape of familial isolated and young-onset pituitary adenomas: prospective diagnosis in AIP mutation carriers. Journal of Clinical Endocrinology and Metabolism 100 E1242-E1254. (doi:10.1210/jc.2015-1869). 
Hernández-Ramírez LC, Tatsi C, Lodish MB, Faucz FR, Pankratz N, Chittiboina P, Lane J, Kay DM, Valdés N, Dimopoulos A, Mills JL \& Stratakis CA 2017 Corticotropinoma as a component of Carney complex. Journal of the Endocrine Society [in press]. (doi:10.1210/ js.2017-00231)

Iacovazzo D, Hernández-Ramírez LC \& Korbonits M 2017 Sporadic pituitary adenomas: the role of germline mutations and recommendations for genetic screening. Expert Review of Endocrinology and Metabolism 12 143-153. (doi:10.1080/17446651.20 17.1306439)

Kirley SD, D’Apuzzo M, Lauwers GY, Graeme-Cook F, Chung DC \& Zukerberg LR 2005a The Cables gene on chromosome $18 \mathrm{Q}$ regulates colon cancer progression in vivo. Cancer Biology and Therapy 4 861-863. (doi:10.4161/cbt.4.8.1894)

Kirley SD, Rueda BR, Chung DC \& Zukerberg LR 2005b Increased growth rate, delayed senescense and decreased serum dependence characterize cables-deficient cells. Cancer Biology and Therapy 4 654-658. (doi:10.4161/cbt.4.6.1732)

Kiyokawa H, Kineman RD, Manova-Todorova KO, Soares VC, Hoffman ES, Ono M, Khanam D, Hayday AC, Frohman LA \& Koff A 1996 Enhanced growth of mice lacking the cyclin-dependent kinase inhibitor function of p27(Kip1). Cell 85 721-732. (doi:10.1016/ S0092-8674(00)81238-6)

Korbonits M, Chahal HS, Kaltsas G, Jordan S, Urmanova Y, Khalimova Z, Harris PE, Farrell WE, Claret FX \& Grossman AB 2002 Expression of phosphorylated p27(Kip1) protein and Jun activation domainbinding protein 1 in human pituitary tumors. Journal of Clinical Endocrinology and Metabolism 87 2635-2643. (doi:10.1210/ jcem.87.6.8517)

Landrum MJ, Lee JM, Benson M, Brown G, Chao C, Chitipiralla S, Gu B, Hart J, Hoffman D, Hoover J, et al. 2016 ClinVar: public archive of interpretations of clinically relevant variants. Nucleic Acids Research 44 D862-D868. (doi:10.1093/nar/gkv1222)

Lee M \& Pellegata NS 2013 Multiple endocrine neoplasia syndromes associated with mutation of p27. Journal of Endocrinological Investigation 36 781-787.

Lek M, Karczewski KJ, Minikel EV, Samocha KE, Banks E, Fennell T, O'Donnell-Luria AH, Ware JS, Hill AJ, Cummings BB, et al. 2016 Analysis of protein-coding genetic variation in 60,706 humans. Nature 536 285-291. (doi:10.1038/nature19057)

Li H \& Durbin R 2010 Fast and accurate long-read alignment with Burrows-Wheeler transform. Bioinformatics 26 589-595. (doi:10.1093/ bioinformatics/btp698)

Lidhar K, Korbonits M, Jordan S, Khalimova Z, Kaltsas G, Lu X, Clayton RN, Jenkins PJ, Monson JP, Besser GM, et al. 1999 Low expression of the cell cycle inhibitor p27Kip1 in normal corticotroph cells, corticotroph tumors, and malignant pituitary tumors. Journal of Clinical Endocrinology and Metabolism 84 3823-3830. (doi:10.1210/ jcem.84.10.6066)

Littlewood TD, Hancock DC, Danielian PS, Parker MG \& Evan GI 1995 A modified oestrogen receptor ligand-binding domain as an improved switch for the regulation of heterologous proteins. Nucleic Acids Research 23 1686-1690. (doi:10.1093/nar/23.10.1686)

Liu NA, Ben-Shlomo A \& Melmed S 2011a Molecular biology of Cushing's disease. In Cushing's Disease, pp 19-32. Eds B Swearingen $\&$ BMK Biller. US: Springer.

Liu NA, Jiang H, Ben-Shlomo A, Wawrowsky K, Fan XM, Lin S \& Melmed S 2011b Targeting zebrafish and murine pituitary corticotroph tumors with a cyclin-dependent kinase (CDK) inhibitor. PNAS 108 8414-8419. (doi:10.1073/pnas.1018091108)

Matsuoka M, Matsuura Y, Semba K \& Nishimoto I 2000 Molecular cloning of a cyclin-like protein associated with cyclin-dependent kinase 3 (cdk 3) in vivo. Biochemical and Biophysical Research Communications 273 442-447. (doi:10.1006/bbrc.2000.2965)

Mizuno S, Tra DT, Mizobuchi A, Iseki H, Mizuno-Iijima S, Kim JD, Ishida J, Matsuda Y, Kunita S, Fukamizu A, et al. 2014 Truncated Cables1 causes agenesis of the corpus callosum in mice. Laboratory Investigation 94 321-330. (doi:10.1038/labinvest.2013.146)

Nakayama K, Ishida N, Shirane M, Inomata A, Inoue T, Shishido N, Horii I, Loh DY \& Nakayama K 1996 Mice lacking p27(Kip1) display increased body size, multiple organ hyperplasia, retinal dysplasia, and pituitary tumors. Cell 85 707-720. (doi:10.1016/S00928674(00)81237-4)

Pellegata NS, Quintanilla-Martinez L, Siggelkow H, Samson E, Bink K, Hofler H, Fend F, Graw J \& Atkinson MJ 2006 Germ-line mutations in p27Kip1 cause a multiple endocrine neoplasia syndrome in rats and humans. PNAS 103 15558-15563. (doi:10.1073/pnas.0603877103)

Pérez-Rivas LG, Theodoropoulou M, Ferrau F, Nusser C, Kawaguchi K, Stratakis CA, Faucz FR, Wildemberg LE, Assie G, Beschorner R, et al. 2015 The gene of the ubiquitin-specific protease 8 is frequently mutated in adenomas causing Cushing's disease. Journal of Clinical Endocrinology and Metabolism 100 E997-E1004.

Rambaud J, Desroches J, Balsalobre A \& Drouin J 2009 TIF1beta/KAP-1 is a coactivator of the orphan nuclear receptor NGFI-B/Nur77. Journal of Biological Chemistry 284 14147-14156. (doi:10.1074/jbc. M809023200)

Reincke M, Sbiera S, Hayakawa A, Theodoropoulou M, Osswald A, Beuschlein F, Meitinger T, Mizuno-Yamasaki E, Kawaguchi K, Saeki Y, et al. 2015 Mutations in the deubiquitinase gene USP8 cause Cushing's disease. Nature Genetics 47 31-38. (doi:10.1038/ng.3166)

Robinson JT, Thorvaldsdottir H, Winckler W, Guttman M, Lander ES, Getz G \& Mesirov JP 2011 Integrative genomics viewer. Nature Biotechnology 29 24-26. (doi:10.1038/nbt.1754)

Roussel-Gervais A, Bilodeau S, Vallette S, Berthelet F, Lacroix A, FigarellaBranger D, Brue T \& Drouin J 2010 Cooperation between cyclin E and p27(Kip1) in pituitary tumorigenesis. Molecular Endocrinology 24 1835-1845. (doi:10.1210/me.2010-0091)

Roussel-Gervais A, Couture C, Langlais D, Takayasu S, Balsalobre A, Rueda BR, Zukerberg LR, Figarella-Branger D, Brue T \& Drouin J 2016 The Cables 1 gene in glucocorticoid regulation of pituitary corticotrope growth and Cushing disease. Journal of Clinical Endocrinology and Metabolism $\mathbf{1 0 1}$ 513-522. (doi:10.1210/jc.2015-3324)

Sakamoto H, Friel AM, Wood AW, Guo L, Ilic A, Seiden MV, Chung DC, Lynch MP, Serikawa T, Munro E, et al. 2008 Mechanisms of Cables 1 gene inactivation in human ovarian cancer development. Cancer Biology and Therapy 7 180-188. (doi:10.4161/cbt.7.2.5253)

Sambugaro S, Di RM, Ambrosio MR, Pellegata NS, Bellio M, Guerra A, Buratto M, Foschini MP, Tagliati F, degli UE, et al. 2015 Early onset acromegaly associated with a novel deletion in CDKN1B 5'UTR region. Endocrine 49 58-64. (doi:10.1007/s12020-015-0540-y)

Shi Z, Li Z, Li ZJ, Cheng K, Du Y, Fu H \& Khuri FR 2015a Cables1 controls p21/Cip1 protein stability by antagonizing proteasome subunit alpha type 3. Oncogene 34 2538-2545. (doi:10.1038/ onc.2014.171)

Shi Z, Park HR, Du Y, Li Z, Cheng K, Sun SY, Li Z, Fu H \& Khuri FR 2015b Cables1 complex couples survival signaling to the cell death machinery. Cancer Research 75 147-158. (doi:10.1158/0008-5472. CAN-14-0036)

Stenson PD, Ball EV, Mort M, Phillips AD, Shiel JA, Thomas NS, Abeysinghe S, Krawczak M \& Cooper DN 2003 Human gene mutation database (HGMD): 2003 update. Human Mutation 21 577-581. (doi:10.1002/humu.10212)

Storr HL, Alexandraki KI, Martin L, Isidori AM, Kaltsas GA, Monson JP, Besser GM, Matson M, Evanson J, Afshar F, et al. 2011 Comparisons in the epidemiology, diagnostic features and cure rate by transsphenoidal surgery between paediatric and adult-onset Cushing's disease. European Journal of Endocrinology 164 667-674. (doi:10.1530/EJE-10-1120)

Stratakis CA, Tichomirowa MA, Boikos S, Azevedo MF, Lodish M, Martari M, Verma S, Daly AF, Raygada M, Keil MF, et al. 2010 The role of germline AIP, MEN1, PRKAR1A, CDKN1B and CDKN2C mutations in http://erc.endocrinology-journals.org

DOI: 10.1530/ERC-17-0131
() 2017 The authors Printed in Great Britain 
causing pituitary adenomas in a large cohort of children, adolescents, and patients with genetic syndromes. Clinical Genetics 78 457-463. (doi:10.1111/j.1399-0004.2010.01406.x)

Susaki E \& Nakayama KI 2007 Multiple mechanisms for p27(Kip1) translocation and degradation. Cell Cycle 6 3015-3020. (doi:10.4161/ cc.6.24.5087)

Tan D, Kirley S, Li Q, Ramnath N, Slocum HK, Brooks JS, Wu CL \& Zukerberg LR 2003 Loss of cables protein expression in human nonsmall cell lung cancer: a tissue microarray study. Human Pathology 34 143-149. (doi:10.1053/hupa.2003.26)

Tichomirowa MA, Barlier A, Daly AF, Jaffrain-Rea ML, Ronchi C, Yaneva M, Urban JD, Petrossians P, Elenkova A, Tabarin A, et al. 2011 High prevalence of AIP gene mutations following focused screening in young patients with sporadic pituitary macroadenomas. European Journal of Endocrinology 165 509-515. (doi:10.1530/EJE-11-0304)

Trivellin G, Correa RR, Batsis M, Faucz FR, Chittiboina P, Bjelobaba I, Larco DO, Quezado M, Daly AF, Stojilkovic SS, et al. 2016 Screening for GPR101 defects in pediatric pituitary corticotropinomas. Endocrine-Related Cancer 23 357-365. (doi:10.1530/ERC-16-0091)

Tsuji K, Mizumoto K, Yamochi T, Nishimoto I \& Matsuoka M 2002 Differential effect of ik3-1/cables on p53- and p73-induced cell death. Journal of Biological Chemistry 277 2951-2957. (doi:10.1074/ jbc.M108535200)

UniProt Consortium; Bateman A, Martin MJ, O'Donovan C, Magrane M, Apweiler R, Alpi E, Antunes R, Arganiska J, Bely B, Bingley M, et al. 2015 UniProt: a hub for protein information. Nucleic Acids Research 43 D204-D212. (doi:10.1093/nar/gku989)

Van der Auwera GA, Carneiro MO, Hartl C, Poplin R, Del Angel G, LevyMoonshine A, Jordan T, Shakir K, Roazen D, Thibault J, et al. 2013 From FastQ data to high confidence variant calls: the Genome Analysis Toolkit best practices pipeline. Current Protocols in Bioinformatics 43 11.10.1-33. (doi:10.1002/0471250953.bi1110s43)
Wang K, Li M \& Hakonarson H 2010a ANNOVAR: functional annotation of genetic variants from high-throughput sequencing data. Nucleic Acids Research 38 e164. (doi:10.1093/nar/gkq603)

Wang N, Guo L, Rueda BR \& Tilly JL 2010b Cables1 protects p63 from proteasomal degradation to ensure deletion of cells after genotoxic stress. EMBO Reports 11 633-639. (doi:10.1038/embor.2010.82)

Williams F, Hunter S, Bradley L, Chahal HS, Storr HL, Akker SA, Kumar AV, Orme SM, Evanson J, Abid N, et al. 2014 Clinical experience in the screening and management of a large kindred with familial isolated pituitary adenoma due to an aryl hydrocarbon receptor interacting protein (AIP) mutation. Journal of Clinical Endocrinology and Metabolism 99 1122-1131. (doi:10.1210/jc.2013-2868)

Wu CL, Kirley SD, Xiao H, Chuang Y, Chung DC \& Zukerberg LR 2001 Cables enhances cdk2 tyrosine 15 phosphorylation by Wee1, inhibits cell growth, and is lost in many human colon and squamous cancers. Cancer Research 61 7325-7332.

Yamochi T, Semba K, Tsuji K, Mizumoto K, Sato H, Matsuura Y, Nishimoto I \& Matsuoka M $2001 \mathrm{ik3-1/Cables} \mathrm{is} \mathrm{a} \mathrm{substrate} \mathrm{for}$ cyclin-dependent kinase 3 (cdk 3). European Journal of Biochemistry 268 6076-6082. (doi:10.1046/j.0014-2956.2001.02555.x)

Zhang H, Duan HO, Kirley SD, Zukerberg LR \& Wu CL 2005 Aberrant splicing of cables gene, a CDK regulator, in human cancers. Cancer Biology and Therapy 4 1211-1215. (doi:10.4161/cbt.4.11.2085)

Zukerberg LR, Patrick GN, Nikolic M, Humbert S, Wu CL, Lanier LM, Gertler FB, Vidal M, Van Etten RA \& Tsai LH 2000 Cables links Cdk5 and $\mathrm{c}-\mathrm{Abl}$ and facilitates Cdk5 tyrosine phosphorylation, kinase upregulation, and neurite outgrowth. Neuron 26 633-646. (doi:10.1016/S0896-6273(00)81200-3)

Zukerberg LR, DeBernardo RL, Kirley SD, D’Apuzzo M, Lynch MP, Littell RD, Duska LR, Boring L \& Rueda BR 2004 Loss of cables, a cyclindependent kinase regulatory protein, is associated with the development of endometrial hyperplasia and endometrial cancer. Cancer Research 64 202-208. (doi:10.1158/0008-5472.CAN-03-2833)

Received in final form 16 May 2017

Accepted 18 May 2017

Accepted Preprint published online 22 May 2017 